\title{
Design of a Monitoring System of Micro-Grid
}

\section{Xiangyang Zhao, Shiyang Liu}

School of Automation Science and Electrical Engineering, Beihang University, Beijing, China.

Email: zhaoxiangyang@buaa.edu.cn,phoebus@asee.buaa.edu.cn

Received September $10^{\text {th }}, 2012$; revised January $10^{\text {th }}, 2013$; accepted January $17^{\text {th }}, 2013$

Copyright (c) 2013 Xiangyang Zhao, Shiyang Liu. This is an open access article distributed under the Creative Commons Attribution License, which permits unrestricted use, distribution, and reproduction in any medium, provided the original work is properly cited.

\begin{abstract}
This paper describes a micro-grid system and its monitoring system. This micro-grid system consists of generation systems, consumer electrical equipments, auxiliary equipments and the monitoring system. All the equipments have 485 communication interfaces. In order to monitor and manage this micro-grid system, we built a monitoring system, which contains modular instrument system and industrial personal computer. In order to keep real time, we adopt some measures in software and hardware. We adopt LABVIEW and its program modules in software and adopt modular instrument system in hardware. Supporting by the software and hardware, the micro-grid system can be safe and stable.
\end{abstract}

Keywords: Micro-Grid; Real Time; The Monitoring System; Communication

\section{Introduction}

With the rapid development of the economy and the growth of power demand, in the past few decades the China power department has paid most of the attention to the large concentrated power, coal-fired power, hydroelectric power, nuclear power, the construction of ultra high voltage and distance transmission power grids. The electric power industry has made great progress and development. With the constant expansion of power grid, the shortcomings of large scale power system are increasingly prominent. Especially in recent years, large area outages have occurred several times all around the world, and the vulnerability of electric grid has exposed.

In order to solve the problems mentioned above, the distributed power generation is put on the agenda. Distributed power generation has less pollution, higher reliability, higher efficiency, flexible installation and many other advantages.

Although the distributed power generation has a lot of advantages, there are also many problems [1]. For example, it is expensive when the distributed power single accesses the grid. Then the distributed power has some difficulties on control. The distributed power generation is an uncontrolled power supply relative to the large power grid. In order to coordinate the contradiction between the large power grid and the distributed power supply, considering the value and benefits between the distributed energy power grid and the user, scholars have put forward the concept of the micro-grid at the begin- ning of this century.

As an important component of the distributed power generation, the micro-grid is a necessary development trend for the future [2-5]. It can not only improve the power supply reliability, but also ease up the pressure on energy conservation and environmental protection [6-8]. This paper describes a micro-grid system and its monitoring system which manages this micro-grid system.

\section{The Micro-Grid System}

\subsection{The Composition of the Micro-Grid System}

Figure 1 shows the micro-grid system which contains

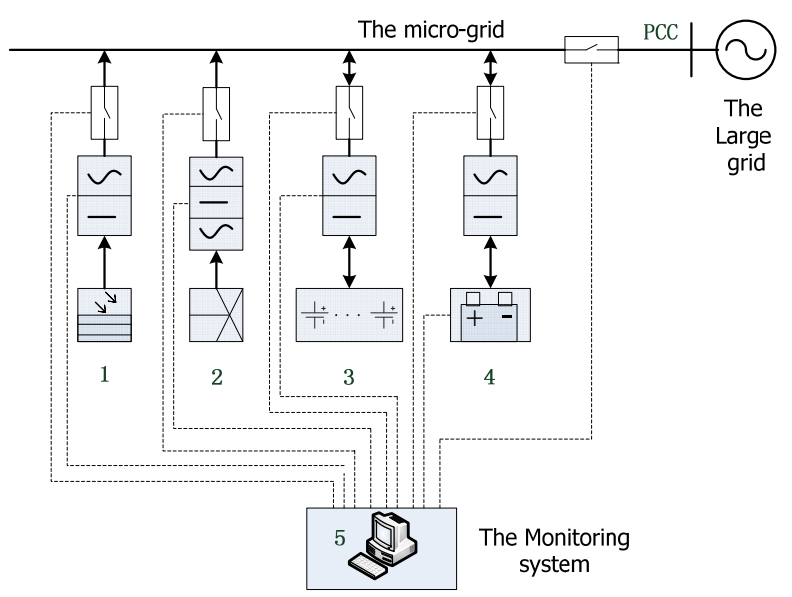

Figure 1. The composition of the micro-grid system. 
five parts. This micro-grid system consists of photovoltaic (pv) power generation system, wind power generation system, super capacitor energy storage system, lithium battery energy storage system, modular instrument system based on PXI and industrial personal computer.

This micro-grid contains two kinds of generation systems. The first is photovoltaic (pv) power generation system. It consists of solar-cell panel, grid inverter, and intelligent switch. The second is wind power generation system, which contains wind generators, converter, and intelligent switch. The demand for more power, combined with interest in clean technologies has driven researchers to develop distributed power generation systems using renewable energy sources, which the two systems both belong to.

In order to achieve the technical characteristics of micro-grid better, electric energy storage technology is regarded as one of the core technologies in micro-grid, which plays an important role in stabilizing electric power system and utilizing renewable energy with high efficiency [9]. There are two energy storage systems in this micro-grid system. One is lithium battery energy storage system which has big storage capacity and can be charged and discharged many times. It can keep the micro-grid operate even if the two generation systems can not generate for some time because of the bad environment or other reasons. The other is super capacitor energy storage system, which can charge and discharge rapidly, so it can help solve some transient problems, which happen when load operates suddenly, or the micro-grid operates from grid mode to island mode.

The dual mode inverter is indispensable to the microgrid, which is in the lithium battery energy storage system [10-12]. When the grid operates normally, it works in grid-connected mode, and the inverter operates in current-control mode as a current-source, controlling the active power and reactive power, so we also call it PQ mode. In this mode, the large grid controls frequency and voltage.

When the large grid failures, the micro-grid will open the grid switch, and work in the island mode. It keeps the voltage and the frequency stability as a voltage source. We call it VF mode. As the grid return to normal, the dual mode inverter closes the grid switch, and works from VF mode to PQ mode.

In order to keep the micro-grid safe and stability, we need to organically combine all the devices in the microgrid. So we built a monitoring system. The monitoring system masters real-time state of all equipments and controls any equipment in any time. For example, when the micro-grid works in island mode, the two energy storage systems are both full of electricity, and the load has low electricity consumption, we need to control the two generation systems to reduce the output to keep the load work normally.

\subsection{The Monitoring System}

The monitoring system monitors real-time running status of all the equipments, and controls all the equipments according to the safe and stable operation requirements. It is very important to ensure real-time for the monitor system. In this micro-grid system, we ensure the system real time through the software and hardware [13].

In the hardware, the whole monitoring system contains PXI communication and control interface equipment and industrial personal computer. The monitoring system gathers equipment information through the 485 communication. In order to guarantee system real time, we adopt point-to-point 485 communication structure instead of the traditional 485 bus structure. It depends on PXI communication and control interface equipment to improve baud rate to 38,400 bps under the data transmission in stable condition. In addition, we adopt the special communication module to ensure the real time and stable. The PXI communication and control interface equipment contains embedded controller, 18-slot backplane, and Industrial RS485/422 serial interface.

The embedded controller is a high-performance Intel Core 2 Quad Q9100-based embedded controller. With its $2.26 \mathrm{GHz}$ quad-core processor, it is ideal for high-performance modular instrumentation and data acquisition applications. The industrial RS485/422 serial interface offers all the features of high-performance NI PXI-843x modules plus high-voltage port-to-port isolation. The indus trial RS485/422 serial interface features high-speed communication with RS485 and RS422 devices at rates of up to $3 \mathrm{Mbit} / \mathrm{s}$ and offers configurable baud rates for data transmissions between 57 baud and 3,000,000 baud to within 1 percent accuracy for nonstandard baud rates and 0.01 percent accuracy for standard baud rates.

In software, we adopt LabVIEW as programming software which is based on a data flow graphical development platform, and it provides intuitive graphical user interface and programming way. Compared with the traditional text programming, LabVIEW is a natural kind of parallel structure of the programming language. In order to insure the real time of the system, especially for realtime of orders, we use multithreading and the parallel structure. When the monitoring system communicates with different equipments, the advantage of parallel structure is more obvious. In order for a system to be a real-time system, all parts of it need to be real-time. For example, even though a program runs in a real-time operating system, it does not mean that the program behaves with realtime characteristics. The program may rely on something that does not behave in real-time, which then causes the program not to behave in real-time.

The status of the grid operation displays in the inter- 
face of the industrial personal computer, which contains warning information, failure message, and so on. The workers can fully grasp the operation condition of the micro-grid and control all the equipments through the monitoring interface.

\section{Software of the Monitoring System}

The program has four functions, collecting data, uploading data, receiving the command, and controlling the devices. Figure 2 shows the basic flowchart of PXI. First, the program initialization contains setting initial value to the corresponding variables. Then, it does not connect to the network, until the network connection is normal. Finally, it begins to work, gathering data, uploading data, receiving the command, and controlling the deceives.

This system gathers data by 485 communications interface, and the modbus protocol. The 485 communication interface is a kind of interface standards, which determines the interface electrical standards and just is the physical layer of a standard. The modbus protocol is used for electronic controller of the universal language. Through this protocol, controller between each other, controller and other equipment in the network can communicate. In order to send data to industrial personal computer, which will store the data for inquiring, the basic program adopts TCP/IP communication module, sending and receiving data.

\section{The Operation of the Monitoring System}

So far, the monitoring system has operated for about one month, and has finished part of the performance tests. The monitoring system can start and shutdown the micro-grid system automatically according to a button in the interface. Now, the system is working normally, and will accept the other aspects of the test on the next step.

\section{Conclusion}

In this paper, it describes a micro-grid, which contains the hardware construction system and the monitoring system. The real time control strategy and the management method of micro-grid were successfully employed

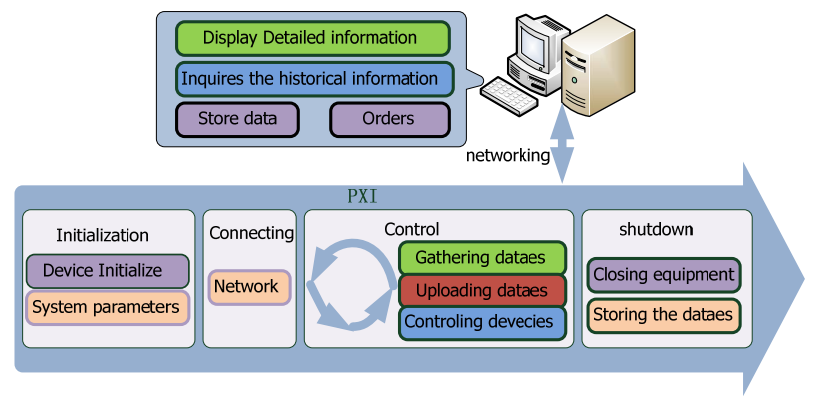

Figure 2. The structure of the monitoring system. in the micro-grid. The monitoring system has used 485 interfaces to communicate with all the facilities. We have taken the corresponding measures to solve the real-time problems from the software and hardware. However, it is need to continue to watch the power grid of the operation, perfect the automatic operation strategy, improve the system reliability and so on.

\section{REFERENCES}

[1] J. Driesen and R. Belmans, "Distributed Generation: Challenges and Possible Solutions," 2006 IEEE Power Engineering Society General Meeting, Montreal, October 2006, p. 8.

[2] C. X. Wu, F. S. Wen and Y. L. Lou, "The Existed Problems and Possible Solutions of Micro-Grid Based on Distributed Generation,” Electric Utility Deregulation and Restructuring and Power Technologies, Nanjing, 6-9 April 2008, pp. 2763-2768.

[3] R. H. Lasseter, "Certs Microgrid," IEEE International Conference on System of Systems Engineering, Vol. 1, 2007, pp. 1-5.

[4] X.-S. Zhou, L.-Q. Cui and Y.-J. Ma, "Research on Control of Micro Grid," Measuring Technology and Mechatronics Automation (ICMTMA), Shanghai, 6-7 January 2011, pp. 1129-1132.

[5] T. Rihit, M. Ned and H. Chris, "Seamless Transfer of Grid-Connected PWM Inverters between Utility-Interactive and Stand-Alone Modes," Seventeenth Annual IEEE Applied Power Electronics Conference and Exposition, Vol. 2, 2002, pp. 1081-1086.

[6] Z. X. Lu, C. X. Wang and Y. Min, "Overview on Microgrid Research,” Automation of Electric Power Systems, Vol. 31, No. 19, 2007, pp. 100-107.

[7] J. Driesen and F. Katiraei, "Design for Distributed Energy Resources,” IEEE Power Energy Magazine, Vol. 3, No. 6, 2008, pp. 30-40.

[8] K. Sheng, L. Kong and Z. P. Qi, “A Survey on Research of Microgrid-A New Power System,” Relay, Vol. 35, No. 12, 2007, pp. 75-81.

[9] T. Shimakage, J. Sumita, N. Uchiyama, T. Kato and Y. Suzuoki, "Supply and Demand Control of Distributed Generators in a Microgrid,” 2008 IEEE Telecommunications Energy Conference, San Diego, 14-18 September 2008, pp. 1-5.

[10] Z. L. Yang, H. Liao, C. S. Wu and H. H. Xu, “Analysis and Selection of Switch for Double Modes Inverter in Micro-Grid System,” International Conference on Electrical Machines and Systems, Wuhan, 17-20 October 2008, pp. 1778-1781.

[11] G. P. Wang, L. Z. Yi, S. F. He, B. Zhang, Z. Z. Yao and B. Wang, "Double-Mode Modulation Based on Limited Trajectories for ANN-SVPWM in PV Grid-Connected Inverter," Control and Decision Conference (CCDC), Xuzhou, 26-28 May 2010, pp. 4272-4277.

[12] H. R. Gu, Z. L. Yang, D. Y. Wang and W. Y. Wu, "Research on Control Method of Double-Mode Inverter with Grid-Connection and Stand-Alone,” Power Electronics 
and Motion Control Conference, 14-16 August 2006, pp. 1-5.

[13] T.-Y. Lee, K.-H. Ha, H.-J. Yoo, J.-W. Seo and M.-C.
Shin, "Research for Data Acquisition Equipment with Micro-Grid System," Electrical and Computer Engineering, Dhaka, 20-22 December 2008, pp. 712-715. 